\title{
The impact of body mass index on age at breast cancer diagnosis and breast cancer phenotype
}

\author{
Olivier Brouckaert ${ }^{1 *}$, An Poppe ${ }^{2}$, Annouschka Laenen², Giuseppe Floris², Karin Leunen², Patrick Berteloot ${ }^{2}$, \\ Frederic Amant ${ }^{2}$, Ignace Vergote ${ }^{1}$, Ann Smeets ${ }^{2}$, Caroline Weltens ${ }^{2}$, Stephanie Peeters ${ }^{2}$, Erik Van Limbergen ${ }^{2}$, \\ Hans Wildiers ${ }^{2}$, Marie-Rose Christiaens ${ }^{2}$, Patrick Neven ${ }^{2}$
}

From Methods in Epidemiology Symposium

Leuven, Belgium. 17 September 2015

\section{Background}

Evidence suggests that premenopausal obesity decreases and postmenopausal obesity increases breast cancer risk. It is unclear why this dual relationship is observed. We here study whether body mass index (BMI) affects (a) age at breast cancer diagnosis and (b) the probability of being diagnosed with a specific breast cancer phenotype, taking menopausal status into account.

\section{Patients and methods}

All patients with non-metastatic operable breast cancer from UZ Leuven diagnosed between January 1, 2000 and December 31, 2013 were included $(n=7020)$. For statistical analysis, linear models and logistic regression were used to study respectively the association between $\mathrm{BMI}$ and age at diagnosis and BMI and breast cancer phenotype by menopausal status. Where necessary, a correction for the relation between BMI and age will be applied, based on publicly available data from the Belgian Health Interview Surveys.

\section{Results}

There was a quadratic relationship between BMI and age at breast cancer diagnosis studying the overall population $(\mathrm{p}<0.0001)$. A $5 \mathrm{~kg} / \mathrm{m} 2$ increase in BMI was associated with the following increases in age at diagnosis: $+1.8 \mathrm{y}(95 \% \mathrm{CI}$ $1.4-2.3 \mathrm{y})$ at $\mathrm{BMI}=18,+1.2 \mathrm{y}(95 \% \mathrm{CI} 0.95-1.5 \mathrm{y})$ at $\mathrm{BMI}=23$ and $+0.6 y$ (95\% CI 0.4-0.9y) at BMI $=28$ (corrected for menopause). Correction for the relation BMI with age are ongoing and not yet available in this abstract.

'Jan Yperman Ziekenhuis, leper, Belgium

Full list of author information is available at the end of the article

The relationship between BMI and the probability of being diagnosed with specific breast cancer phenotypes will be presented during the congress.

\section{Conclusion}

The relation between BMI and age at diagnosis and between BMI and the chance of being diagnosed with specific breast cancers is complex. New analyses taking into account the relation between BMI and age are ongoing. We look forward to present the final results on the congress.

\section{Authors' details \\ ${ }^{1} J a n$ Yperman Ziekenhuis, leper, Belgium. ${ }^{2}$ Multidisciplinary Breast Centre, University Hospitals Leuven, Leuven, Belgium.}

Published: 17 September 2015

doi:10.1186/2049-3258-73-S1-P6

Cite this article as: Brouckaert et al:: The impact of body mass index on age at breast cancer diagnosis and breast cancer phenotype. Archives of Public Health 2015 73(Suppl 1):P6.

Submit your next manuscript to BioMed Central and take full advantage of:

- Convenient online submission

- Thorough peer review

- No space constraints or color figure charges

- Immediate publication on acceptance

- Inclusion in PubMed, CAS, Scopus and Google Scholar

- Research which is freely available for redistribution 